\title{
The Neural Circuitry Involved in the Reading of German Words and Pseudowords: A PET Study
}

\section{Peter Hagoort}

Max Planck Institute for Psycholinguistics

\section{Peter Indefrey}

Max Planck Institute for Psycholinguistics and Heinrich Heine University

\section{Colin Brown}

Max Planck Institute for Psycholinguistics

\author{
Hans Herzog \\ Institute of Medicine, Research Center Jülich
}

\section{Helmuth Steinmetz and Rüdiger J. Seitz \\ Heinrich Heine University}

\begin{abstract}
Silent reading and reading aloud of German words and pseudowords were used in a PET study using $\left({ }^{15} \mathrm{O}\right)$ butanol to examine the neural correlates of reading and of the phonological conversion of legal letter strings, with or without meaning. The results of 11 healthy, right-handed volunteers in the age range of 25 to 30 years showed activation of the lingual gyri during silent reading in comparison with viewing a fixation cross. Comparisons between the reading of words and pseudowords suggest the involvement of the middle temporal gyri in retrieving both the phonological and semantic code for words. The reading of pseudowords activates the left inferior frontal
\end{abstract}

\section{INTRODUCTION}

Most models of normal reading assume that reading words of a familiar language is a complex process composed of a number of subcomponents, including access to orthographic and phonological word forms and activation of the associated word meaning (Perfetti, 1999). Evidence for the fractionation of word reading into its constituent components has been gained from both normal reading research and from reading impairments in different types of dyslexic patients. In addition, in recent years a number of positron emission tomography (PET) studies suggest that different brain areas are involved in different aspects of word reading (e.g., Beauregard et al., 1997; Bookheimer, Zeffiro, Blaxton, Gaillard, \& Theodore, 1995; Herbster, Mintun, Nebes, \& Becker, 1997; Howard

gyrus, including the ventral part of Broca's area, to a larger extent than the reading of words. This suggests that this area might be involved in the sublexical conversion of orthographic input strings into phonological output codes. (Pre)motor areas were found to be activated during both silent reading and reading aloud. On the basis of the obtained activation patterns, it is hypothesized that the articulation of high-frequency syllables requires the retrieval of their concomitant articulatory gestures from the SMA and that the articulation of lowfrequency syllables recruits the left medial premotor cortex.

et al., 1992; Petersen, Fox, Posner, Mintun, \& Raichle, 1988; Petersen, Fox, Snyder, \& Raichle, 1990; Price, Moore, \& Frackowiak, 1996; Price, Moore, Humphreys, \& Wise, 1997; Price et al., 1994; Price, Wise, \& Frackowiak, 1996; Rumsey et al., 1997; Wise et al., 1991). However, exactly which areas in the brain subserve which aspect of word processing is still a matter of debate. The lack of agreement between the results of different PET studies on word reading might in part be due to subtle differences in the procedures to detect changes in regional cerebral blood flow ( $\mathrm{rCBF}$ ), differences in rate duration of the stimulus presentations, in the instruction to the subjects, or in the choice of the comparison scans (see Price et al., 1994; Price, Moore, et al., 1996). Before a detailed sketch of the neural architecture of word reading can be given, additional studies have to be done 
to replicate and extend the current studies and to further assess the seemingly sizable consequences of subtle methodological differences.

The present study seeks to replicate and extend existing PET studies on word processing.

The first extension relates to the linguistic material. In contrast to most previous PET studies on word reading, which used English words and English subjects, we presented German words (and pseudowords) to native speakers of German. Language-specific differences between the orthographic and phonological makeup of words might have consequences for the areas found to be active during different aspects of word processing. Languages like English and German have some noticeable differences in their lexical regularities. English, for instance, has a substantially more opaque relation between the way words are written and pronounced than German, which has a relatively transparent orthography. English readers, therefore, often have to rely on a lexical route in reading aloud, whereas German readers can rely more strongly on a nonlexical route. This latter route exploits the regularities in the relation between letters and sounds (cf. Coltheart, Curtis, Atkins, \& Haller, 1993). This might have consequences for processes involved in pronouncing written word forms (cf. Katz \& Feldman, 1983; Monsell, Patterson, Graham, Hughes, \& Milroy, 1992) and for the brain manifestations of these processes. Cross-linguistic comparisons are therefore crucial to determine the commonalities and differences in networks of activated areas for word processing in different languages. This holds not only across language families (cf. studies on reading Japanese kana; Kuriki, Hirata, Fujimaki, \& Kobayashi, 1996; Law et al., 1991; Sakurai et al., 1993; and studies on reading of Japanese kanji; Sakurai et al., 1992) but also within Indo-European languages.

A second relevant extension relates to the reading aloud of legal nonwords (pseudowords). Two recent studies compared the reading aloud of pseudowords with overt word reading (Herbster et al., 1997; Rumsey et al., 1997). Herbster et al. reported increased activation in the left inferior frontal cortex for reading aloud of pseudowords and irregular words, compared to reading aloud of words with a regular mapping of graphemes to phonemes. This activation was attributed to the increased phonological processing for irregular words and pseudowords. Rumsey et al. had subjects read aloud pseudowords and irregular words. Additional tasks were to indicate for pairs of pseudowords which one sounded like a real word and to select the real word from pairs of words and pseudohomophones (e.g., boal, bole). For the reading aloud task, Rumsey et al. observed increased activations in the left superior temporal gyrus and bilaterally in the pre- and postcentral gyri when pseudowords were contrasted with irregular words. The decision tasks resulted in increased activation in the left inferior frontal cortex, stronger for pseudowords than for irregular words. However, in both studies, the matching of words and pseudowords was not optimal. Words and pseudowords were only matched for length (Herbster et al.) or in addition for initial letter and number of syllables (Rumsey et al.). Words and pseudowords were not matched for bigram and biphone frequencies or for syllable frequencies. Several recent studies have shown that listeners and readers are sensitive to probability differences among the phonotactic and orthographic patterns of the sublexical segments in syllables and words (Pitt \& McQueen, 1998; Seidenberg, 1987; Vitevich \& Luce, 1998; Vitevitch, Luce, Charles-Luce, \& Kemmerer, 1997). Similarly, syllable frequencies are known to affect word processing (Levelt \& Wheeldon, 1994; Zwitserlood, Schriefers, Lahiri, \& van Donselaar, 1993). Matching letter strings on these sublexical aspects might be important, especially if one wants to investigate similarities and differences between the conversion of orthography to phonology for written words and pseudowords. Therefore, we tried to replicate the results of these earlier studies with word and pseudoword letter strings that were better matched in their sublexical characteristics (but see below).

The crucial scans in our study involved the passive reading and the reading aloud of both German words and German pseudowords. In this context we were particularly interested in those areas that have shown activation in some but not all PET studies on word processing and for which claims have been made with respect to their functional significance. These regions of interest, which will be discussed below, include the extrastriate occipital cortex, temporal and temporoparietal cortex, inferior frontal areas including Broca's area, cerebellum, and (pre)motor areas including the supplementary motor area (SMA).

In most studies on single-word reading, visual presentation of letterlike strings elicits increased cerebral blood flow not only in striate areas but also in the extrastriate cortex. The increased blood flow in the extrastriate cortex is seen bilaterally and at lateral sites (Howard et al., 1992; Petersen et al., 1988, 1990). PET studies, however, differ in their results for letter strings that can be assumed to involve lexical processing. These letter strings are either real words or pseudowords that obey the phonotactic and orthographic constraints of the language. In the Petersen et al. (1990) study, subjects were scanned during silent processing of false fonts, consonant strings, real words, and pseudowords. For real words and pseudowords, subtraction of a fixation scan resulted in increased cerebral blood flow in the left medial extrastriate cortex. No such response was seen for false fonts or consonant strings. This pattern of results led to the conclusion that the left medial extrastriate cortex plays a crucial role in accessing the visual input lexicon (Petersen et al., 1988; Petersen, Fox, Posner, Mintun, \& Raichle, 1989; Posner \& Raichle, 1994). 
Howard et al. (1992), however, observed a trend but no significant increase in rCBF in the left medial extrastriate cortex after subtracting false font strings from real words. In their study, a strong response was seen in the left posterior middle temporal gyrus. The authors, therefore, hypothesize that this latter area is critically involved in access to the visual input lexicon. They argue that their finding is more compatible with lesion data from patients with specific reading disorders, because of its closeness to the angular gyrus, an area classically associated with the storage of visual word forms (e.g., Déjerine, 1891). Recently, Menard, Kosslyn, Thompson, Alpert, and Rauch (1996) reported supportive evidence for the involvement of areas close to the angular gyrus in wordform processing. This evidence was based on a PET study on the encoding of words and pictures.

One of the procedural differences between the Petersen et al. (1990) and the Howard et al. (1992) study is that in the former subjects were required to silently read the words, whereas in the latter they had to read the words aloud. The potentially stronger involvement of phonological word representations in the reading aloud task compared to silent reading might have shifted the activation focus away from visual processing areas (cf. Price et al., 1994). To control for this potential task difference, in one scan we had subjects read words silently, and in another scan they had to read words aloud.

However, even the Price et al. (1994) study, which replicated the presentation conditions of Petersen et al. (1990) failed to replicate the original finding. This failure to replicate might have been related to one, seemingly subtle difference between the original study and the replication by Price et al. In the Price et al. study, distribution of blood flow in silent reading was contrasted to viewing of false fonts, whereas Petersen et al. found increased activity in the left medial extrastriate cortex by comparing word reading with viewing a fixation cross. A fixation cross is a visual stimulus with clearly less wordlike aspects than false fonts. Because in our study we compared blood flow distribution in reading words to viewing a fixation cross instead of false fonts, we might be able to determine whether this difference between the Price et al. and the Petersen et al. studies was crucial for observing significant activity increase in the left medial extrastriate cortex. However, the results of recent functional magnetic resonance imaging (fMRI) (Indefrey et al., 1997) and PET (Chertkow, Bub, Beauregard, Hosein, \& Evans, in press) studies that carefully controlled the visual characteristics of the stimulus sets suggest that these occipital activations are largely due to the visual complexity of the written wordlike stimuli, not to their lexical or sublexical characteristics.

The alternative claim that the left posterior middle temporal gyrus is crucial for accessing the visual input lexicon (Beauregard et al., 1997; Howard et al., 1992) is also not consistently supported. Bookheimer et al. (1995) failed to find activation in this region in a PET study on object naming and word reading. They, however, observed activations in the left inferior temporal gyrus and the nearby fusiform gyrus that were indicative of a role of these areas in visual word-form processing. Data from intracranial recordings (Nobre, Allison, \& McCarthy, 1994) are compatible with a contribution of the fusiform gyrus to the processing of wordlike stimuli.

On the whole, one has to conclude that with respect to the retrieval of visual word forms neither the role of the left extrastriate areas nor that of the left middle temporal cortex is sufficiently clarified by the available brain-imaging data.

Areas that have been classically associated with phonological processing involve the left temporal and temporo-parietal cortex (e.g., Luria, 1947). To a large extent, recent PET studies seem to support the view that these areas play a crucial role in the phonological analysis of wordlike stimuli (Démonet et al., 1992; Démonet, Price, Wise, \& Frackowiak, 1994; Frith, Friston, Liddle, \& Frackowiak, 1991; Herholz et al., 1994; Howard et al., 1992; Paulesu, Frith, \& Frackowiak, 1993; Petersen et al., 1989; Price et al., 1994; Rumsey et al., 1997; Wise et al., 1991). Petersen et al. (1989) asked subjects to make rhyme decisions on pairs of printed words. This condition resulted in a blood flow increase in the left temporo-parietal cortex. In the Démonet et al. study (1992), subjects were required to monitor for a particular phoneme in a series of auditorily presented pseudowords, which led to activation in the left superior temporal gyrus (and to a lesser extent in Broca's area and in the right superior temporal regions). Passive listening to pseudowords resulted in a bilateral blood flow increase in the posterior superior temporal gyri (Wise et al., 1991). For reading aloud, increased blood flow has been reported for the left middle temporal gyrus (Howard et al., 1992). Finally, for word repetition, activation has been found bilaterally, in the superior temporal cortices (Herholz et al., 1994). However, although PET studies have confirmed temporal and temporo-parietal involvement in the processing of single-word phonology, there is quite some variation between different studies in the activated areas within these gross anatomical structures. Again, a better understanding of the different task requirements and presentation parameters in these studies is required to appreciate the significance of the observed anatomical variations. In addition, as for other aspects of word processing (cf. Hagoort, Brown, \& Swaab, 1996; Price et al., 1994), right-hemisphere involvement has been reported in a substantial number of PET studies on the processing of word phonology, suggesting a role for the right temporal cortex in addition to left homologue areas.

A third region of interest in the context of this study is the left inferior frontal gyrus, including Broca's area. 
Results of recent brain-imaging studies suggest a role for this area in the processing of word phonology. Tasks involving rhyme judgment on pairs of auditorily presented syllables (Zatorre, Evans, Meyer, \& Gjedde, 1992; Zatorre, Meyer, Gjedde, \& Evans, 1996), or letters (Paulesu et al., 1993), and other letter-sound tasks (Sergent, Zuck, Levesque, \& MacDonald, 1992) have resulted in increased blood flow in the left inferior frontal gyrus. In a recent fMRI study (Pugh et al., 1996; Shaywitz et al., 1995), one of the tasks was to determine whether visually presented pairs of pseudowords rhymed. The rhymejudgment task elicited strongly left lateralized activation in the inferior frontal gyrus of males, whereas females showed a more bilateral activation of the inferior frontal gyri. Although some of these results have been interpreted as evidence for the involvement of Broca's area in verbal memory (e.g., Paulesu et al., 1993), it is by no means clear whether this is the only or major functional interpretation of the inferior frontal gyrus involvement in phonological processing. In our study, we investigate the possible role of the inferior frontal gyrus in either grapheme-to-phoneme conversion or in assembling a phonological output code by comparing reading aloud and silent reading of both words and pseudowords (cf. Herbster et al., 1997; Rumsey et al., 1997).

Finally, we were interested in areas that are engaged in the preparation and execution of articulation. Both cerebellum (especially left and medial parts) and (pre)motor areas are known to be relevant in this re- spect (cf. Fiez \& Raichle, 1997; Indefrey \& Levelt, in press).

In this study a series of six scans was run on each of the subjects. Two of these scans were the control states, one measuring $\mathrm{rCBF}$ during a resting state and the other during the presentation of a crosshair with the same presentation parameters as the word and pseudoword stimuli. Four scans were taken during the presentation of orthographic strings, which either formed existing German words (two scans) or German pseudowords (two scans). For all five scans with stimulus presentations, the stimuli were presented for a duration of 758 msec at a rate of one stimulus per $1.5 \mathrm{sec}$.

\section{RESULTS}

\section{Silent Reading vs. Fixation Cross}

Both silent reading of words and pseudowords led to bilateral activation of medial and lateral extrastriate areas and to activity in the left lower precentral gyrus. This latter activation indicates that even in silent reading articulation is prepared internally. Additional areas of activation included the right insula and for the pseudowords in particular, the right middle fusiform gyrus, the right precentral gyrus, the anterior cingulate, and the right superior parietal lobule. The coordinates of the activation peaks, with their corresponding maximal $t$ values, are presented in Table 1 .

Table 1. Areas of Significant rCBF Increase during Silent Reading of Words and Pseudowords, Relative to Viewing a Fixation Cross.

\begin{tabular}{|c|c|c|c|c|c|c|}
\hline \multirow[b]{2}{*}{ Region } & \multicolumn{3}{|c|}{ Words-Fixation Cross } & \multicolumn{3}{|c|}{ Pseudowords-Fixation Cross } \\
\hline & $\begin{array}{c}\text { Extent } \\
(B A)\end{array}$ & $\begin{array}{c}\text { Talairach } \\
(x, y, x)\end{array}$ & $t-\max$ & $\begin{array}{c}\text { Extent } \\
(B A)\end{array}$ & $\begin{array}{c}\text { Talairach } \\
(x, y, z)\end{array}$ & $t-\max$ \\
\hline \multirow[t]{2}{*}{ L Lingual Gyrus } & 19 & $-4,-59, \quad 0$ & 3.78 & & & \\
\hline & $18 / 19$ & $-19,-90,-6$ & 8.69 & $18 / 19$ & $-35,-82,-6$ & 7.30 \\
\hline \multirow[t]{2}{*}{ R Lingual Gyrus } & 18 & $7,-68, \quad 5$ & 3.86 & $18 / 17$ & $9,-74, \quad 5$ & 6.09 \\
\hline & $18 / 19$ & $19,-86,-6$ & 4.15 & 19 & $24,-87,-6$ & 5.98 \\
\hline R Middle Fusiform Gyrus & & & N.S. & $37 / 19$ & $39,-55,-16$ & 4.31 \\
\hline R Superior Parietal Lobule & & & N.S. & $7 / 19$ & $31,-62, \quad 35$ & 2.81 \\
\hline R Anterior Insula & 15 & $39, \quad 26,-1$ & 3.57 & 14 & $29, \quad 11,3$ & 3.32 \\
\hline L Postcentral Gyrus & $1 / 2 / 3$ & $-49,-14, \quad 32$ & 3.03 & & N.S. & \\
\hline L Precentral Gyrus & $4 / 6$ & $-54, \quad-5, \quad 27$ & 4.52 & $6 / 4$ & $-57,-6, \quad 28$ & 5.69 \\
\hline R Precentral Gyrus & & N.S. & & $6 / 4$ & $35,-17, \quad 45$ & 3.60 \\
\hline L/R Anterior Cingulate Gyrus & & N.S. & & 32 & $-1,-3, \quad 39$ & 4.86 \\
\hline
\end{tabular}

The brain regions, Brodmann's area (BA), location coordinates, and maximal $t$ values associated with areas of significant rCBF increase. The location coordinates of the pixel with the highest $t$ values are taken from the CBA database and reported according to the stereotactic atlas of Talairach and Tournoux (1988), with $x$ referring to left $(-)$ and right $(+), y$ referring to the anterior-posterior dimension relative to the anterior commissure line (+ : anterior to the AC line; $-:$ posterior to the $\mathrm{AC}$ line), and $z$ referring to inferior-superior dimension relative the anterior commissure-posterior commissure (AC-PC) line ( - : inferior to the AC-PC line; + : superior to the AC-PC line). The macro-anatomical description of blood flow changes in terms of regions and Brodmann's areas is based on the atlas of Talairach and Tournoux. The specified BAs indicate location as well as extent of the blood flow changes. L: Left; R: Right. 


\section{Reading Aloud vs. Silent Reading of Words and Pseudowords}

Areas that were more strongly activated during reading aloud than during silent reading of words and pseudowords (see Table 2) were identified in (1) the superior temporal gyrus bilaterally, close to Heschl's gyri (2) the middle temporal gyrus, bilaterally for words and right for pseudowords (3) the midline cerebellum and mesencephalon (4) the left and right premotor and sensorimotor cortices (5) the bilateral extrastriate visual cortices, and (6) for words, bilateral thalamic regions. Apart from the extrastriate activations these findings are remarkably similar to the ones reported by Price, Moore et al. (1996) for their comparison of reading aloud versus silent reading of words.

In addition, the right anterior insula was activated during reading aloud of words, but not of pseudowords. The right superior parietal lobule and the right anterior cingulate were more active during reading aloud than silent reading of pseudowords. Especially the cerebellar activation was much stronger for reading aloud of pseudowords than for reading aloud of words.

\section{Silent Reading vs. Reading Aloud of Words and Pseudowords}

Areas of increased rCBF during silent reading of words and pseudowords (see Table 3) included (1) the left and right angular gyrus (2) the medial posterior cingulate, and (3) the superior and inferior frontal areas mainly on the lateral surface. The silent reading of words, but not of pseudowords, resulted in additional rCBF increase in the left and right supramarginal gyrus and the right anterior fusiform gyrus. The silent reading of pseudowords, but not of words, led to rCBF increase in the medial precuneus/cuneus. This pattern of results is very similar to the recent report of consistent cortical blood

Table 2. Areas of Significant rCBF Increase during Reading Aloud Relative to Silent Reading of Words and Reading Aloud Relative to Silent Reading of Pseudowords

\begin{tabular}{|c|c|c|c|c|c|c|}
\hline \multirow[b]{2}{*}{ Region } & \multicolumn{2}{|c|}{ Aloud-Silent Word Reading } & \multirow[b]{2}{*}{$t-\max$} & \multicolumn{3}{|c|}{ Aloud-Silent Pseudoword Reading } \\
\hline & $\begin{array}{l}\text { Extent } \\
(B A)\end{array}$ & $\begin{array}{l}\text { Talairach } \\
(x, y, x)\end{array}$ & & $\begin{array}{c}\text { Extent } \\
(B A)\end{array}$ & $\begin{array}{l}\text { Talairach } \\
(x, y, z)\end{array}$ & $t-\max$ \\
\hline L Cuneus & 18 & $-18,-101,-2$ & 4.19 & $17 / 18$ & $-4,-93, \quad 4$ & 4.07 \\
\hline R Cuneus & $\begin{array}{l}18 \\
18\end{array}$ & $\begin{array}{rrr}20, & -97, & 4 \\
12, & -94, & 15\end{array}$ & $\begin{array}{l}3.29 \\
3.60\end{array}$ & $17 / 18$ & $7,-95, \quad 4$ & 4.77 \\
\hline $\begin{array}{l}\text { L Fusiform Gyrus } \\
\text { R Fusiform Gyrus }\end{array}$ & $\begin{array}{l}37 / 19 \\
19 / 37\end{array}$ & $\begin{array}{rr}-37, & -57,-11 \\
25, & -68,-11\end{array}$ & $\begin{array}{l}4.92 \\
4.77\end{array}$ & & $\begin{array}{l}\text { N.S. } \\
\text { N.S. }\end{array}$ & \\
\hline $\begin{array}{l}\text { L Lingual Gyrus } \\
\text { R Lingual Gyrus }\end{array}$ & & $\begin{array}{l}\text { N.S. } \\
\text { N.S. }\end{array}$ & & $\begin{array}{l}19 \\
19\end{array}$ & $\begin{array}{rr}-14,-66, & 0 \\
14,-88, & -1\end{array}$ & $\begin{array}{l}4.35 \\
4.92\end{array}$ \\
\hline $\begin{array}{l}\text { L Superior Temporal Gyrus } \\
\text { R Superior Temporal Gyrus }\end{array}$ & $\begin{array}{l}22 / 42 \\
42 / 22\end{array}$ & $\begin{array}{rrr}-56, & -19, & 2 \\
56, & -28, & 8\end{array}$ & $\begin{array}{l}3.92 \\
6.95\end{array}$ & $\begin{array}{l}38 / 41 / 42 / 22 \\
38 / 41 / 42 / 22 / 40\end{array}$ & $\begin{array}{rr}-54,-20, & 14 \\
46,-36, & 13\end{array}$ & $\begin{array}{l}5.47 \\
8.18\end{array}$ \\
\hline $\begin{array}{l}\text { L Middle Temporal Gyrus } \\
\text { R Middle Temporal Gyrus }\end{array}$ & $\begin{array}{l}21 \\
21\end{array}$ & $\begin{array}{rrr}-61, & -23, & -9 \\
48, & -15, & -3\end{array}$ & $\begin{array}{l}2.99 \\
4.48\end{array}$ & $21 / 37$ & $\begin{aligned} \text { N.S. } & \\
47,-42, & 7\end{aligned}$ & 4.03 \\
\hline R Superior Parietal Lobule & & N.S. & & 7 & $32,-60, \quad 48$ & 3.49 \\
\hline $\mathrm{R}$ Insula & 14 & $27, \quad 11, \quad 10$ & 3.68 & & N.S. & \\
\hline $\begin{array}{l}\text { L Pre/Postcentral Gyrus } \\
\text { R Pre/Postcentral Gyrus }\end{array}$ & $\begin{array}{l}4 / 6 \\
4 / 6 / 1 / 2 / 3\end{array}$ & $\begin{array}{rrr}-56, & -7, & 14 \\
49, & -6, & 39\end{array}$ & $\begin{array}{l}7.00 \\
5.10\end{array}$ & $\begin{array}{l}4 / 6 / 1 / 2 / 3 \\
4 / 6 / 1 / 2 / 3\end{array}$ & $\begin{array}{rll}-58, & -9, & 20 \\
53, & -6, & 27\end{array}$ & $\begin{array}{l}8.19 \\
4.19\end{array}$ \\
\hline R Anterior Cingulate Gyrus & $32 / 10$ & $10, \quad 20,-7$ & 3.95 & 24 & $11, \quad 12, \quad 34$ & 4.62 \\
\hline $\begin{array}{l}\text { Subcortical: } \\
\text { L/R Cerebellum } \\
\text { L/R Mesencephalon } \\
\text { L Thalamus } \\
\text { R Thalamus }\end{array}$ & & $\begin{array}{rrr}1, & -66, & -16 \\
3, & -38, & -4 \\
-14, & -12, & 14 \\
12, & -31, & 7\end{array}$ & $\begin{array}{l}3.72 \\
5.78 \\
3.30 \\
5.22\end{array}$ & & $\begin{array}{l}-2,-51,-11 \\
3,-32,-10 \\
\text { N.S. } \\
\text { N.S. }\end{array}$ & $\begin{array}{r}12.01 \\
5.72\end{array}$ \\
\hline
\end{tabular}

The brain regions, Brodmann's area (BA), location coordinates, and maximal $t$ values associated with areas of significant rCBF increase. The location coordinates of the pixel with the highest $t$ values are taken from the CBA database and reported according to the stereotactic atlas of Talairach and Tournoux (1988), with $x$ referring to left $(-)$ and right $(+), y$ referring to the anterior-posterior dimension relative to the anterior commissure line (+ : anterior to the AC line; $-:$ posterior to the AC line), and $z$ referring to inferior-superior dimension relative the anterior commissure-posterior commissure (AC-PC) line (- : inferior to the AC-PC line; $+:$ superior to the AC-PC line). The macro-anatomical description of blood flow changes in terms of regions and Brodmann's areas is based on the atlas of Talairach and Tournoux. The specified BAs indicate location as well as extent of the blood flow changes. L: Left; R: Right. 
Table 3. Areas of Significant rCBF Increase during Reading Aloud of Words and Pseudowords Relative to Silent Reading of Words and Pseudowords

\begin{tabular}{|c|c|c|c|c|c|c|}
\hline \multirow[b]{2}{*}{ Region } & \multicolumn{3}{|c|}{ Silent-Aloud Word Reading } & \multicolumn{3}{|c|}{ Silent-Aloud Pseudoword Reading } \\
\hline & $\begin{array}{l}\text { Extent } \\
(B A)\end{array}$ & $\begin{array}{l}\text { Talairach } \\
(x, y, x)\end{array}$ & $t-\max$ & $\begin{array}{l}\text { Extent } \\
(B A)\end{array}$ & $\begin{array}{l}\text { Talairach } \\
(x, y, z)\end{array}$ & $t-\max$ \\
\hline L/R Cuneus/Precuneus & & N.S. & & $19 / 18 / 7$ & $2,-76, \quad 28$ & 3.14 \\
\hline R Anterior Fusiform Gyrus & $36 / 37 / 20$ & $36,-33,-20$ & 2.93 & & N.S. & \\
\hline L Angular Gyrus & 39 & $-42,-66, \quad 30$ & 8.34 & 39 & $-52,-56, \quad 36$ & 4.89 \\
\hline R Angular Gyrus & $39 / 19$ & $40,-59, \quad 30$ & 4.48 & & & \\
\hline R Angular/Middle Temporal Gyrus & & & & $39 / 19$ & $36,-68, \quad 35$ & 4.85 \\
\hline L Supramarginal Gyrus & 40 & $-48,-36, \quad 37$ & 5.18 & & N.S. & \\
\hline R Supramarginal Gyrus & 40 & $47,-27, \quad 38$ & 4.09 & & N.S. & \\
\hline L/R Posterior Cingulate Gyrus & 31 & $-8,-36, \quad 31$ & 3.98 & $23 / 31$ & $-1,-38, \quad 31$ & 6.02 \\
\hline $\begin{array}{l}\text { L Dorsal Middle Frontal Gyrus } \\
\text { R Dorsal Middle Frontal Gyrus }\end{array}$ & $8 / 9$ & $\begin{array}{l}-37, \quad 15, \quad 34 \\
\text { N.S. }\end{array}$ & 4.05 & $\begin{array}{l}8 / 9 \\
8 / 9\end{array}$ & $\begin{array}{rrr}-39, & 25, & 35 \\
27, & 31, & 41\end{array}$ & $\begin{array}{l}8.43 \\
4.41\end{array}$ \\
\hline L Dorsolateral Prefrontal Cortex & $46 / 10$ & $-40, \quad 41, \quad 17$ & 5.32 & $10 / 46$ & $-41, \quad 51, \quad 5$ & 4.15 \\
\hline L Superior Frontal Gyrus & & & & $10 / 46$ & $-12, \quad 50, \quad 12$ & 3.90 \\
\hline R Dorsolateral Prefrontal Cortex & 46 & $42, \quad 43, \quad 11$ & 3.76 & $46 / 10$ & $40, \quad 44, \quad 5$ & 3.43 \\
\hline L Inferior/Middle Frontal Gyrus & 47 & $-36, \quad 51,-6$ & 3.76 & $47 / 10 / 3$ & $-30, \quad 50,-6$ & 5.07 \\
\hline R Inferior/Middle Frontal Gyrus & 47 & $36,42,-6$ & 3.11 & & N.S. & \\
\hline
\end{tabular}

The brain regions, Brodmann's areas (BA), location coordinates, and maximal $t$ values associated with areas of significant rCBF increase. The location coordinates of the pixel with the highest $t$ values are taken from the CBA database and reported according to the stereotactic atlas of Talairach and Tournoux (1988), with $x$ referring to left $(-)$ and right $(+), y$ referring to the anterior-posterior dimension relative to the anterior commissure line ( + : anterior to the AC line; - : posterior to the AC line), and $z$ referring to inferior-superior dimension relative the anterior commissure-posterior commissure (AC-PC) line ( - : inferior to the AC-PC line; + : superior to the AC-PC line). The macro-anatomical description of blood flow changes in terms of regions and Brodmann's areas is based on the atlas of Talairach and Tournoux. The specified BAs indicate location as well as extent of the blood flow changes. L: Left; R: Right.

flow decreases during active visual tasks relative to passive viewing (Shulman et al., 1996).

\section{Words vs. Pseudowords}

Reading aloud and also silent reading resulted in precentral gyrus activation, suggesting that even in silent reading articulatory preparation cannot be completely suppressed. Silent reading and reading aloud thus seem to be different in degree, but the processes and brain areas involved are overlapping to a large extent (see the Discussion).

For the relatively subtle comparisons of words and pseudowords, we therefore decided to average together the scans for silent reading of words and reading aloud of words, as well as the scans for silent and overt pseudoword reading. In this way we improved the power for a direct comparison between word and pseudoword processing during reading.

Most prominently, the left inferior frontal gyrus (Brodmann's areas 47/45) was more strongly activated during the reading of pseudowords than during word reading. This area of activation included the ventral part of Broca's area (see Figure 1A, f and 1B, e, f). The activation in this area was stronger for the reading aloud than for the silent reading comparison.
Additional areas of stronger activation in pseudoword reading (see Table 4) were found in (1) the left and right extrastriate cortices (2) the left and right middle fusiform gyrus (3) the left superior temporal gyrus (4) the left premotor cortex, and (5) the cerebellum. In testing the interactions between the separate subtractions for the reading aloud and silent reading conditions, only the cerebellar activation showed a significant interaction. This activation was mostly due to the reading aloud comparison of pseudowords and words. If articulated, pseudowords resulted in stronger cerebellar activation than words.

The opposite subtraction (i.e., words - pseudowords; see Table 4) resulted in stronger activations in (1) the left lingual gyrus (2) the right superior temporal gyrus (3) both the left and right middle temporal gyrus (4) the supplementary motor area, and (5) central parts of the cingulate.

\section{Fixation Cross vs. Rest}

We also compared the activation differences in the two control states. The fixation cross minus rest comparison resulted only in activation of visual areas, bilaterally and mostly lateral. In contrast, rest minus fixation cross showed activation in a large number of areas. These 
Figure 1. Sagittal (A) and horizontal (B) sections of regions that were more activated during the reading of words (silent + aloud, top rows) and of regions that were more activated during the reading of pseudowords (silent + aloud, bottom rows) The section levels are indicated on a template image to the right of the activation images. The color-coded activations are based on $t$ maps, with red signifying higher levels of significance than yellow. Areas of activation are projected onto an MRI scan converted to the standard anatomy of the computerized CBA atlas (Thurfjell et al., 1995) in the same way as the PET images. In the horizontal sections, the left side of the brain appears on the right, and the right side of the brain on the left. For words relative to pseudowords, right superior temporal activation is seen in (A), section a, and (B), section a. Bilateral middle temporal gyrus activations are seen in (A), sections a and c. SMA and cingulate activations are seen in (A), section b; SMA activation furthermore in (B), section d. For pseudowords relative to words left inferior frontal gyrus activation is seen in (A), section $f$ and (B), sections e and $\mathrm{f}$. In addition, midcerebellar and fusiform gyri activations are seen in (A), sections e and $\mathrm{f}$, and (B), section e. Left superior temporal gyrus activation is seen in (B), section $\mathrm{f}$. Left medial premotor cortex activations are shown in (A), section e, and (B) sections $\mathrm{g}$ and $\mathrm{h}$.

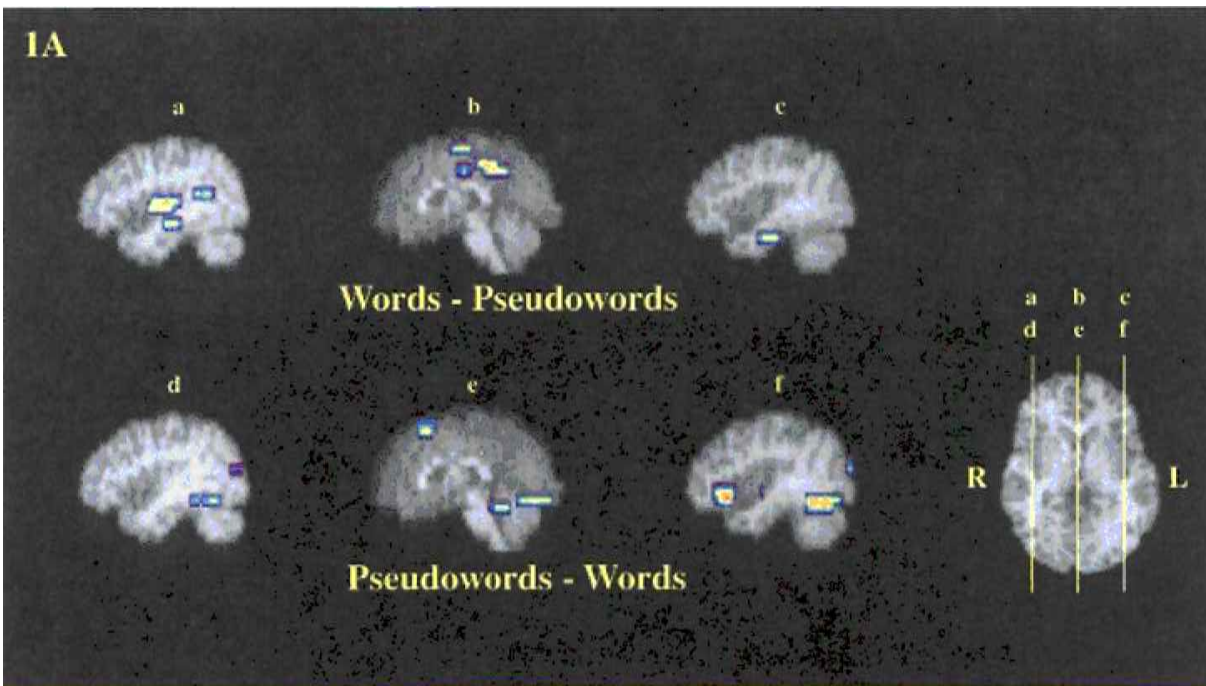

$1 \mathrm{~B}$

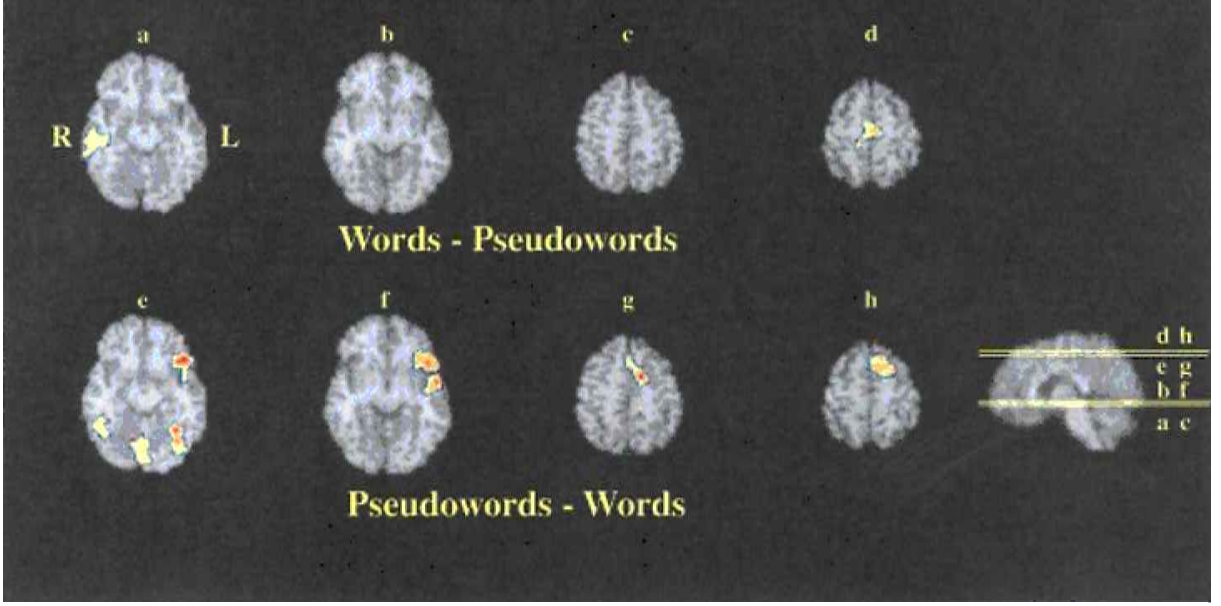

included (Talairach coordinates of pixels with the maximal $t$ values are given in parentheses) the lingual gyrus $(-2,-64,6)$, the left and right superior parietal lobule $(-24,-43,36 ; 29,-44,36)$, the left postcentral gyrus $(-25$, $-33,44)$, an extensive part of the right precentral gyrus, the right insula $(29,3,-2)$, the right hippocampus (22, $-9,-14)$, the right superior frontal gyrus $(8,21,48)$, the left middle frontal gyrus $(-29,3,53)$, and the right orbital gyrus $(8,27,-13)$.

\section{DISCUSSION}

\section{Extrastriate Visual Areas}

The reading of both words and pseudowords led to substantial activation in both the lateral and medial extrastriate visual cortex when compared to the simple fixation of a crosshair. In contrast to the results of the
Petersen et al. (1990) study, the medial activation was not restricted to the left hemisphere but was obtained bilaterally. Petersen et al. (1990) have suggested that the left medial extrastriate activation is related to the orthographic analysis of letter strings in wordlike stimuli. Our data, however, do not support a special role for left extrastriate areas in the reading of orthographically legal and pronounceable letter strings in German. Although one could speculate that these differences reflect language-specific differences in the processing of English and German words, such an explanation is not very likely in the light of the results of a recent fMRI study (Indefrey et al., 1997). This study explicitly tested visual length and complexity against letter strings, using similar German pseudowords as were used here, as well as false fonts. The results of this study showed that the medial extrastriate activations disappeared for the subtraction "pseudowords minus false fonts" when the false fonts 
Table 4. Areas of Significant rCBF Increase during Reading of Pseudowords Relative to Words and during Reading of Words Relative to Pseudowords (Collapsed over Silent Reading and Reading Aloud)

\begin{tabular}{|c|c|c|c|}
\hline Region & $\begin{array}{c}\text { Extent } \\
(B A)\end{array}$ & $\begin{array}{l}\text { Talairach } \\
(x, y, z)\end{array}$ & $t-\max$ \\
\hline & \multicolumn{3}{|c|}{ Pseudowords-Words } \\
\hline R Superior Occipital Gyrus & 19 & $24,-67,29$ & 4.84 \\
\hline L Middle Occipital Gyrus & 18 & $-27,-86, \quad 15$ & 4.37 \\
\hline R Middle Occipital Gyrus & 18 & $25,-83, \quad 10$ & 3.39 \\
\hline L Middle Fusiform Gyrus & $37 / 19$ & $-34,-55,-11$ & 5.66 \\
\hline R Middle Fusiform Gyrus & $37 / 19$ & $44,-48,-10$ & 3.19 \\
\hline L. Superior Temporal Gyrus & 22 & $-57,-6,-2$ & 4.78 \\
\hline $\begin{array}{l}\text { L Superior Frontal Gyrus } \\
\text { (Premotor Cortex) }\end{array}$ & $6 / 8$ & $-16,-2, \quad 46$ & 6.15 \\
\hline L Inferior Frontal Gyrus & $47 / 45$ & $-46, \quad 17, \quad-8$ & 5.83 \\
\hline \multirow{3}{*}{$\begin{array}{l}\text { Subcortical: } \\
\text { L/R Cerebellum }\end{array}$} & \multirow{2}{*}{\multicolumn{2}{|c|}{$12,-43,-16$}} & \\
\hline & & & 4.78 \\
\hline & \multicolumn{3}{|c|}{ Words-Pseudowords } \\
\hline L Lingual Gyrus & 19 & $-18,-48, \quad 0$ & 3.16 \\
\hline \multirow[t]{2}{*}{ R Superior Temporal Gyrus } & $22 / 39$ & $61,-36, \quad 18$ & 3.85 \\
\hline & $22 / 42$ & $38,-23, \quad 8$ & 4.72 \\
\hline L Middle Temporal Gyrus & $21 / 20$ & $-50,-34,-12$ & 5.61 \\
\hline \multirow[t]{2}{*}{ R Middle Temporal Gyrus } & 21 & $54,-47, \quad 7$ & 5.56 \\
\hline & 21 & $57,-27,-10$ & 3.18 \\
\hline L/R Anterior Cingulate Gyrus & $24 / 23$ & $11,-20, \quad 38$ & 6.18 \\
\hline L/R Paracentral Lobule (SMA) & 6 & $-3,-19, \quad 51$ & 3.39 \\
\hline
\end{tabular}

The brain regions, Brodmann's areas (BA), location coordinates, and maximal $t$ values associated with areas of significant rCBF increase. The location coordinates of the pixel with the highest $t$ values are taken from the CBA database and reported according to the stereotactic atlas of Talairach and Tournoux (1988), with $x$ referring to left $(-)$ and right $(+), y$ referring to the anterior-posterior dimension relative to the anterior commissure line (+ : anterior to the AC line; - : posterior to the AC line), and $z$ referring to inferior-superior dimension relative the anterior commissure-posterior commissure (AC-PC) line ( - : inferior to the AC-PC line; $+:$ superior to the AC-PC line). The macro-anatomical description of blood flow changes in terms of regions and Brodmann's areas is based on the atlas of Talairach and Tournoux. The specified BAs indicate location as well as extent of the blood flow changes. L: Left; R: Right.

were carefully matched in length to the pseudowords, and reappeared for the subtraction "strings of false fonts" minus "single false fonts." These results clearly indicate that differences in the overall visual shape are responsible for the medial extrastriate activations, rather than processes specifically related to the visual input lexicon.

The reading of pseudowords resulted in activation of the middle fusiform gyri, which was not seen for words. Both the left and right middle fusiform gyrus are known to be related to the processing of letter strings (Nobre et al., 1994). Presumably, the processing of letter strings is easier for words than for pseudowords. It is a wellestablished finding that more frequent or familiar words are processed faster and more accurately than infrequent or unfamiliar words. Existing letter strings (words) have a higher familiarity than legal, but nonexisting letter strings (pseudowords) and are therefore easier to process. Moreover, the possible contribution of word-level activation to the processing of letter strings in existing words (McClelland \& Rumelhart, 1981) might result in differential activation for pseudowords and words in this part of the left and right fusiform gyrus. Price, Moore, et al. (1996) found a strong increase of activation in the left and right middle fusiform gyrus with faster presentation rates of word stimuli. Our data suggest that this area is not only sensitive to the rate at which letter strings have to be processed but also to the difficulty of letter string processing.

The stronger activation of the left lingual gyrus during the reading of words compared to the reading of pseudowords supports the conclusion of Price, Moore, et al. (1996) that the function of this area in reading is different from that of the adjacent fusiform gyrus. What exactly its function is in reading, however, remains to be seen. 
SMA, Motor, Premotor, and Cerebellar Areas

Not only words and pseudowords that were read aloud but also words that were read silently led to activation of (pre)motor areas. Although we explicitly asked our subjects to suppress internal vocalization while reading words and pseudowords silently, activity most likely related to the preparation of articulation was observed. This finding is compatible with earlier reports in the literature (Frith, Kapur, Friston, Liddle, \& Frackowiak, 1995; Price et al., 1994; Price, Wise, et al., 1996) and clearly indicates that, independent of task requirements, a number of areas are standardly and implicitly recruited during the processing of wordlike stimuli. Interestingly, though, cerebellar activation was only seen when the articulatory movements were actually executed but never during silent reading. This contrasts with the findings of Price et al. (1994), who also observed cerebellar activation during silent reading. Moreover, the articulation of pseudowords resulted in a substantially larger cerebellar activation than the articulation of words, indicating the greater effort involved in pronouncing pseudowords than words.

Activation of cortical motor areas was seen when letter strings had to be read aloud. These areas included the lateral premotor cortex, bilaterally, which was more strongly activated when the words and pseudowords had to be articulated.

An interesting dissociation was seen in the comparison of words and pseudowords between the left medial premotor cortex and the SMA. The left medial premotor cortex showed increased blood flow for pseudowords compared to words, whereas compared to pseudowords the reading and pronouncing of words resulted in increased blood flow to the SMA (see Figure $1 \mathrm{~A}, \mathrm{~b}$, e and 1B, $\mathrm{d}, \mathrm{g}, \mathrm{h}$ ).

As we report in the Methods section, there was a frequency difference between the syllables that formed the pseudowords and the syllables of which the words were composed. The pseudowords contained more lowfrequency syllables, and the words contained more highfrequency syllables. It has been argued that precompiled articulatory routines are available for the high-frequency syllables of one's native language. These precompiled articulatory routines can be retrieved as units from a so-called mental syllabary (Levelt \& Wheeldon, 1994). Access to such a syllabary is argued to greatly reduce the computational load relative to a segment-by-segment assembly of articulatory programs. Such a segment-bysegment assembly is required for the low-frequency syllables, for which no precompiled routines are available in a mental syllabary. Recent lexico-statistical results support the plausibility of such a mental syllabary. Schiller, Meyer, Baayen, and Levelt (1996) found that for Dutch not more than 500 different syllables make up $85 \%$ of the speech syllables that occur in the CELEX lexical database for Dutch ( 42.38 million words), whereas the total number of syllable types in Dutch is in the order of 12,000. Similar results were obtained for English and German. For English the 500 most frequent syllables covered $80 \%$ of all the syllable tokens in a large lexical database. Of the total number of 10,724 syllable types in German, the 500 most frequent syllable types accounted for $85 \%$ of all the syllable tokens in a German phonological word-form lexicon (Schiller, 1998).

Given the larger number of infrequent syllables in the pseudowords than in the words of our study, the concomitant articulatory gestures might have been less easily available or less practiced for the pseudowords than for the words. The increased midline cerebellar activation can be interpreted as indicating the increased articulatory effort for the low-frequency syllables. In addition, the SMA might be part of the network that is involved in accessing precompiled articulatory routines for high-frequency syllables, whereas the left medial premotor cortex seems to be more involved in the segment-by-segment assembly of low-frequency syllables. Alternatively, one might consider the possibility that for real words there exist precompiled motor codes, reducing the articulatory processing load for these words when spoken in isolation. The stronger left premotor cortex activation would then be due to the assembly of an articulatory program for pseudowords. Clearly, this issue requires further investigation.

Unexpectedly, right anterior insula activation was seen in both reading of words and pseudowords and was stronger when words were read aloud than during silent reading. Especially the precentral gyrus of the left insula has been shown to be involved in the motor planning of speech (Dronkers, 1996). However, it is unclear whether a similar language-specific role can be attributed to the right insula.

\section{Inferior and Dorsolateral Frontal Areas}

Most importantly, the reading of pseudowords resulted in higher activation in left inferior frontal cortex compared to the reading of words. This activation included the ventral part of Broca's area. In the light of other evidence from recent brain-imaging studies, it is likely that this activation is related to phonetic/phonological processing (Démonet et al., 1992, 1994; Herbster et al., 1997; Paulesu et al., 1993; Pugh et al., 1996; Rumsey et al., 1997; Zatorre et al., 1992). However, just as in the Herbster et al. study, the activation in our study had a more ventral focus than the activations observed in studies using phonological tasks, including rhyme judgment tasks (cf. Zatorre et al., 1996), in which more dorsal parts of Broca's area were activated. These results have been taken as evidence that Broca's area is important for phonetic processing and more in particular is involved 
in (subvocal) articulation (Frith et al., 1995). However, as others have already noticed (e.g., Zatorre et al.), it is most likely that Broca's area consists of different subregions, perhaps associated with different functions. The more ventral activation that both Herbster et al. and we observed is presumably more related to phonological recoding than to subvocal articulation. During phonological recoding the orthographic input string is converted into a phonological representation. It is a very robust finding in studies of reading that phonological recoding is slower and less accurate for pseudowords than for words, because for words a phonological representation is available in long-term memory, whereas for pseudowords such a representation has to be assembled through sublexical grapheme-to-phoneme conversions (Coltheart et al., 1993). Phonological recoding operations are thus more strongly involved in the reading of pseudowords than words, which might have resulted in the stronger activation that we observed for pseudowords in the left inferior frontal cortex, including the orbital gyrus (BA 47) and the ventral part of Broca's area. This interpretation is compatible with the findings of Pugh et al. These authors reported frontal activations, including the lateral orbital gyrus that were elicited in a nonword rhyme judgment task. This task forced subjects to assemble a phonological representation through sublexical conversion.

The similarity between the frontal activations obtained in our study and those in comparable studies with English materials (Herbster et al., 1997; Pugh et al., 1996) suggests that the neural circuitry of a nonlexical route in reading is the same for readers of German and of English.

\section{Temporal Lobe Areas}

Bilateral superior temporal gyrus activation was obtained when subjects were reading aloud, due to subjects' hearing their own voice.

The left middle temporal gyrus was more strongly activated during the reading aloud of words but not of pseudowords. In contrast, the right middle temporal gyrus showed increased activation for reading aloud of both words and pseudowords. This supports earlier claims that the left middle temporal gyrus is crucial for the activation of phonological word forms (Price et al., 1994). The role of the right middle temporal gyrus is less clear, but because we did not find it activated during silent reading, it might also be involved in some form of phonological processing, either of the spoken input or the to-be-spoken output.

Middle temporal gyrus activation was also stronger for words than pseudowords, bilaterally. In addition to the involvement of the middle temporal cortex in phonological processing, the stronger activation for words is consistent with the claim that the middle temporal gyri also play a role in the processing of the word meanings associated with the activated word forms (Pugh et al., 1996). Note, however, that left frontal areas that are also claimed to be involved in the processing of word meaning (e.g., Petersen et al., 1990) were not found to be more strongly activated in words than pseudowords. This fits with the view that the left inferior prefrontal cortex is activated under conditions of effortful retrieval, maintenance, or controlled processing of semantic information but not when semantic information is accessed automatically and in the absence of further task-related processing (Fiez, 1997). Silent and overt reading of words are not assumed to require such strategic control of lexical-semantic processing. This view is supported by the finding in neuropsychological studies that Broca's aphasics show normal automatic semantic priming effects, but that controlled semantic priming is sometimes impaired in these patients (Hagoort, 1993, 1997; Ostrin \& Tyler, 1993).

As has been found before (Pugh et al., 1996), the middle temporal cortex seems to be involved in both the processing of phonological word forms and word meaning. The involvement of the right temporal lobe in the processing of word meaning is in line with other evidence from the recent brain-imaging literature, suggesting a right-hemisphere involvement in certain aspects of word processing, including the retrieval of semantic aspects of words (Hagoort et al., 1996; Price et al., 1994).

\section{The Angular and Supramarginal Gyrus}

The left angular gyrus has classically been seen as a crucial processing station in connecting visual and phonological word-form information (Déjerine, 1891; Geschwind, 1979). Recent brain-imaging studies have not provided unequivocal evidence in support of this classical view. Petersen et al. (1990) did not find activation during word-form processing in this or adjacent parietal areas. Bookheimer et al. (1995) found some activation, but the same area was activated with pictures as input. Menard et al. (1996), however, observed increased activation of the angular and supramarginal gyrus in the comparison of viewing words versus viewing pictures. Similar activations were observed during reading of Japanese kana words relative to the reading of kanji characters (Law et al., 1991; but see Sakurai et al., 1993). These data support the findings of Howard et al. (1992) and their claim for a visual-graphemic wordform area near the margin of the angular gyrus.

Our results do not provide additional evidence in support of a special role of the angular and the supramarginal gyrus in reading. Overall, no evidence could be obtained for a region that is dedicated to visual word-form processing. Presumably, extrastriate visual areas may be generally important for processing of familiar visual stimuli, including letter strings (cf. Bookheimer et al., 1995).

Increased rCBF was seen bilaterally in the angular and 
supramarginal gyri in silent reading compared to reading aloud of both words and pseudowords, in addition to a whole range of other areas (see Table 3), including the cingulate, the cuneus/precuneus, and a number of frontal regions. This network of areas is very reminiscent of the outcome of a recent reanalysis of nine studies on the processing of visual stimuli by Shulman and colleagues (Shulman et al., 1996, 1997). Across these nine studies a very consistent pattern of deactivation was seen during active visual tasks relative to passive viewing. For more difficult language-related tasks, blood flow decreases were most pronounced in the parietal lobe. According to the authors, these decreases might reflect deactivations that are necessary for active task processing or the interruption of ongoing processing during a more passive state by the active task. In our case, reading aloud arguably is a more active task than silent reading. The deactivations during reading aloud are thus most likely due to the increased task demands or task-related processes, such as monitoring one's own voice.

\section{Attentional Effects}

Overall, visual areas were more activated during the reading aloud of words and pseudowords than during silent reading. This was also found when the reading of pseudowords was compared to the reading of words. Most likely these effects were attentional effects. Attentional modulation of visual input in the extrastriate cortex has been reported before (Heinze et al., 1994). It seems that with increased task requirements (reading aloud versus silent reading) and with the processing of more complex stimuli (pseudowords versus words) enhanced processing already takes place at early processing stages. Activations in the right anterior cingulate gyrus (aloud minus silent pseudoword reading) and the thalamus (aloud minus silent word reading) have also been related to attentional demands (Heinze et al.).

\section{The Rest Condition}

In the rest minus fixation subtraction a substantial number of activated areas were obtained. Similar results have been reported by Shulman et al. (1996). This outcome illustrates that one has to be careful in using rest as a baseline condition. Many studies insert a scan with a rest condition in which subjects are usually asked to empty their mind, whatever that may mean. The major disadvantage of the rest condition is that the unconstrained task requirement might induce all kinds of mental activity that are outside the control of the experimenter. This is not to say that presenting a fixation cross is the ideal control condition. To a certain degree similar criticisms apply in this case. In general, sound experimental methodology requires not only an explicit account of the cognitive activities that are induced by the activation scans, but also of the cognitive activities during the control scans.

\section{Conclusions}

Despite differences between English and German in terms of orthographic and phonotactic regularities, the circuitry involved in the processing of German wordlike letter strings seems to be similar to what has been reported for English. This is not a trivial outcome because the differences in orthographic transparency between English and German might very well have led to a shift in the balance between lexical and nonlexical routes of reading and thereby to dissimilarities in the activation patterns for reading English and German letter strings.

The middle fusiform gyri seem to play a central role in the processing of letter strings. The (left) middle temporal gyrus is involved in retrieving phonological word forms, whereas the left inferior frontal gyrus plays a role in the phonological recoding of orthographic input strings at a sublexical level. In contrast to previous PET studies on word reading, these results were obtained under the exclusion of differential contributions from the transitional probabilities of the sublexical segments (phonemes and letters) of syllables and words.

The articulation of high-frequency syllables presumably requires the retrieval of their concomitant articulatory gestures from the SMA, whereas the articulation of low-frequency syllables has a stronger involvement of the left premotor cortex. Detailed follow-up studies are required to more specifically test these latter claims.

\section{METHODS}

\section{Subjects}

Eleven volunteers participated in this study (eight males). For technical reasons, the data of one additional subject could not be analyzed. All subjects were consistent right handers according to their scores on two handedness tests (Oldfield, 1971; Steingrüber, 1971). Subjects were in the age range of 25 to 30 years, with a mean age of 26.8 years. All subjects were native speakers of German. All subjects were in good health with no history of neurological or psychiatric disease. They gave written informed consent in accordance with the Declaration of Helsinki. The study was approved by the Ethics Committee of the Heinrich Heine University, Düsseldorf.

\section{Positron Emission Tomography Scanning}

The rCBF was measured after intravenous bolus injection of $\left({ }^{15} \mathrm{O}\right)$ butanol, using the eight-ring Scanditronix PC4096-15WB PET camera. This PET camera has an optimal spatial resolution (full width at half maximum, 
FWHM) of $4.9 \mathrm{~mm}$ in plane and a slice distance of 6.5 mm (Rota Kops, Herzog, Schmid, Holte, \& Feinendegen, 1990). The axial field of view was $105 \mathrm{~mm}$, covering the brain from the dorsal part of the motor cortex down to the cerebellar nuclei. For attenuation correction, a transmission scan was obtained prior to the emission scans using a rotating ${ }^{68} \mathrm{Ge}$ pin source. The 15 PET image slices were reconstructed with a Hanning filter to an effective image resolution (FWHM) of $9 \mathrm{~mm}$.

The subjects underwent six sequential rCBF measurements, with a 15-min pause between sequential scans. PET scanning started at the time of the intravenous injection of the tracer into the right brachial vein. For each scan, approximately $40 \mathrm{mCi}(1.5 \mathrm{MBq})\left({ }^{15} \mathrm{O}\right)$ butanol was injected as a bolus and subsequently flushed with a 10-mL saline solution. The arterial tracer concentration was measured by an automatic blood sampling system (Eriksson, Bohm, Kesselberg, \& Holte, 1988) via an intraarterial cannula that prior to PET scanning had been placed into the left brachial artery under local anesthesia. The local tissue concentration was sampled in list mode, from which single-frame autoradiographic images of 40-sec duration were calculated, starting with the entry of the tracer into the brain. These images were calculated in all 15 PET planes. In addition, a dynamic sequence of frames of 2 sec was obtained for a slice through the basal ganglia and the thalamus.

For rCBF quantification, a combined dynamic-autoradiographic approach was applied (Herzog, Seitz, Tellmann, Schlaug, \& Müller-Gärtner, 1996). In this approach, the delay between the arterial input curve and the tissue concentration, the dispersion, the partition coefficient, and the $\mathrm{rCBF}$ are determined for a cortical region of interest (ROI), using the arterial input function and a least-square fit of the corresponding time-activity curve over $100 \mathrm{sec}$ as input data. On average, the partition coefficient was found to be 0.77 for white and gray matter (Herzog et al.). On the basis of these data, the autoradiographic images were converted pixel by pixel into parametric rCBF-images. Shifts in global CBF due to hemodynamic differences related to raised or depressed $\mathrm{PaCO} 2$ levels among the individual scans were corrected to the global CBF of the rest scan according to Olesen (1974). The global CBF was assessed from ROIs covering the whole brain. For $t$-map calculation, residual global CBF differences between scans were corrected by linear normalization to a mean global CBF of $50 \mathrm{~mL} /$ $100 \mathrm{~g} \bullet \min$.

\section{Experimental Tasks}

Each of the four scans with linguistic stimuli consisted of 80 letter strings. Each letter string was presented for a period of $758 \mathrm{msec}$, followed by a blank screen for another $758 \mathrm{msec}$.

All orthographic strings consisted of mono- and bisyllables with an exceptional three syllable string. The strings varied in length between three and eight graphemes. Between the four lists of stimuli, words and pseudowords were matched as closely as possible for length and number of syllables. Both words and pseudowords consisted on average of 5.1 letters and 1.8 syllables. Words and pseudowords were also closely matched in terms of their bigram and biphone frequencies. These frequencies were determined from the CELEX lexical data base for German containing $\mathbf{5 . 4}$ million tokens for written German, and 530,000 tokens for spoken German. The log mean bigram frequencies were 12.44 and 12.07 for words and pseudowords, respectively; the respective biphone frequencies were 9.86 and 9.55 . However, there was a difference in the frequencies of the syllabic structure between words and pseudowords. Spoken syllable frequencies were computed from the CELEX lexical database for spoken German, containing 880,000 syllable tokens. The syllables that made up the words had a mean frequency of 1288, whereas the mean syllable frequency for the pseudowords was 989. Moreover, there was a difference in the number of syllable types for words and pseudowords. The words contained 139 different syllable types, and the pseudowords contained 241 syllable types. Importantly, the distribution of high- and lowfrequency syllables was also different between words and pseudowords. The words contained $58 \%$ syllable types with a frequency higher than 100 and $19 \%$ syllable types with a frequency below 6 . The pseudoword stimuli counted $42 \%$ syllable types with a frequency above 100 and $42 \%$ with a frequency below 6 . So far, brain-imaging studies comparing words and pseudowords have not controlled for syllable frequency. Neither did we. This, however, might be important in future studies in the light of our results and in the light of other empirical evidence in the literature (Levelt \& Wheeldon, 1994). Nevertheless, given the careful matching at the level of orthographic and phonological structure, differential patterns of activation for words and pseudowords can be reliably attributed to lexical status and/or syllabic processing.

The two word lists consisted of well-known German nouns. The two pseudoword lists contained letter strings that were derived from existing German nouns by changing one or more letters. To guarantee the absence of activation of existing German words, these items were judged by three independent native speakers of German for their similarity with existing words in German. Only items were selected for which judges could not readily produce close analogues that formed German words. All pseudowords were in accordance with the phonotactic and the orthographic constraints of German.

In the first experimental task the subjects had to silently read German words. In the instruction they were told that they were going to be presented with a number of isolated words that in no way made up a story or had any other obvious relation to each other. Subjects were asked to read these words attentively and silently but 
without internally vocalizing them. Subjects were explicitly told that they did not have to remember the words for later recall. In the second experimental task, subjects had to silently read pseudowords. They were told that they were going to be presented with letter strings that did not form German words. Subjects were asked to silently read these strings as attentively as possible, again without internal vocalizations and without attempting to find existing German word analogues for the letter strings. The third experimental task consisted of reading aloud pseudowords. Subjects were told to pronounce these letter strings in a calm voice and to try to pronounce them smoothly, without hesitations and restarts. In addition, subjects were made aware of the fact that some of the letter strings could be pronounced in more than one way and that in these cases they should pronounce them in the way they prefer. The fourth experimental task consisted of reading aloud German words.

\section{Control Tasks}

One control task consisted of a crosshair presented at the center of screen with exactly the same presentation duration and with the same rate of presentation as the orthographic strings in the experimental tasks. In this scan subjects were asked to attentively look at the fixation cross. This control task was performed during the first scan for half of the subjects and during the last scan for the other half of the subjects.

The other control task was a resting condition in which subjects had their eyes open and were requested to empty their mind and to think of nothing in particular for a period of $2 \mathrm{~min}$. This second control task was performed during the last of the series of six scans for half of the subjects and during the first scan for the other half of the subjects.

\section{Procedures}

All scans were performed in a quiet darkened room with only low-level background noise produced by the scanner. The subjects were placed in supine position on the bed of the PET scanner. The subject's head was located in the center of the tomographic scanner and fixed by placing it in an individually molded cushion containing a rapidly hardening jelly. Evaluation of a stable head position throughout the examination was done by laser alignment along the cantho-meatal line before and after the session.

Stimuli were presented in the center of a high-resolution VDU-monitor (Digital VT340), which was placed in an oblique orientation toward the subject's head at a distance of about $90 \mathrm{~cm}$. Apart from a small window around the field of presentation, the monitor was covered by a black sheet. In addition, the periphery of the visual field was covered by a black cloth. Letter strings subtended a visual angle of $2^{\circ}$ to $3^{\circ}$. Stimulus presenta- tion was under computer control and started conjointly with the bolus injection of the radioactive solution.

Subjects were instructed about the task immediately before the emission scans. In the reading aloud conditions, subjects were told to read the words aloud in a normal pace and without correcting errors in their pronunciation. The order of tasks was varied between subjects, with half of the subjects having the reversed order of the experimental and control tasks as the other half of the subjects.

\section{Data Analysis}

Image evaluation was performed with the help of the new version of the computerized brain atlas (CBA) of Bohm and Greitz (Thurfjell, Bohm, \& Bengtsson, 1995). As described earlier in more detail (Seitz et al., 1990, 1997), the rCBF images were transformed into standard brain anatomy using transformation parameters determined for each individual. Standardization yielded 21 axial image slices that were $6.43 \mathrm{~mm}$ apart with a matrix of $128 \times 128$ pixels of $2.55 \times 2.55 \mathrm{~mm}$ each. Image standardization compensated for minimal misalignments between the PET scans (Thurfjell et al., 1995). To exclude rCBF values from extracerebral tissue components, the standard images were thresholded at $30 \mathrm{~mL} / 100 \mathrm{~g} \bullet \mathrm{min}$. In addition, the images were filtered with a mean filter of $18 \mathrm{~mm}$ to account for residual anatomical variability between subjects. For each comparison, subtraction images as well as descriptive $t$ maps of the rCBF changes were calculated pixel by pixel using local standard deviation. For omnibus testing we followed the approach of Roland, Levin, Kawashima, and Akerman (1993), combining a pixel threshold with a threshold for clusters of contiguous pixels. The rCBF changes compared to the control condition were thresholded at a $t$ value of 1.83 (corresponding to an uncorrected $p<0.05$ for one-tailed comparisons). To partially control for multiple comparisons and to correct for the autocorrelation of adjacent pixels that is limited by the spatial resolution (FWHM) of the reconstructed PET images, only clusters of at least 40 contiguous suprathreshold pixels in the PET image slices were accepted as significant. This predominantly descriptive analysis is similar to theoretical cluster analysis approaches that incorporate the degree of smoothness in the images (Friston, Worsley, Frackowiak, Mazziotta, \& Evans, 1994; Worsley, Evans, Marrett \& Neelin, 1992). In a comparison of the approach adopted here performed on a different data set (with identical parameters of smoothing as well as pixel and cluster thresholds) and a Statistical Parametric Mapping analysis (SPM96) with a comparable degree of smoothing, clusters of at least 40 contiguous suprathreshold pixels roughly corresponded to an uncorrected $p<0.01$ in the SPM analysis. Given our hypothesis-driven approach, we adopted this relatively liberal threshold to avoid false 
negatives. Regions that were not expected to be active should be taken as merely descriptive.

\section{Acknowledgments}

The authors are grateful to Harry Uylings and Niels Schiller for their comments on an earlier version of this paper. This research was supported by grant 400-56-384 from the Netherlands Organization for Scientific Research to Colin Brown, Peter Hagoort, and Peter Indefrey.

Reprint requests should be sent to Peter Hagoort, Max Planck Institute for Psycholinguistics, Wundtlaan 1, NL-6525 XD Nijmegen, The Netherlands, or via e-mail: peha@mpi.nl..

\section{REFERENCES}

Beauregard, M., Chertkow, H., Bub, D., Murtha, S., Dixon, R, \& Evans, A. (1997). The neural substrate for concrete, abstract, and emotional word lexica: A positron emission tomography study. Journal of Cognitive Neuroscience, 9, 441-461.

Bookheimer, S. Y., Zeffiro, T. A., Blaxton, T., Gaillard, W., \& Theodore, W. (1995). Regional cerebral blood flow during object naming and word reading. Human Brain Mapping, 3, 93-106.

Chertkow, H., Bub, D., Beauregard, M., Hosein, C., \& Evans, A. (in press). Visual and orthographic components of single word processing: A positron emission tomography study. Brain.

Coltheart, M., Curtis, B., Atkins, P., \& Haller, M. (1993). Models or reading aloud: Dual-route and parallel-distributed-processing approaches. Psychological Review, 100, 589-608.

Déjerine, J. (1981). Sur un cas de cécité verbale agraphie, suivi d'autopsie. Mémoires de la Société Biologique, 4, 6190.

Démonet, J-F., Chollet, F., Ramsay, S., Cardebat, D., Nespoulous, J-L., Wise, R., Rascol, A., \& Frackowiak, R. (1992). The anatomy of phonological and semantic processing in normal subjects. Brain, 115, 1753-1768.

Démonet, J-F., Price, C., Wise, R., \& Frackowiak, R. S. J. (1994). Differential activation of right and left posterior sylvian regions by semantic and phonological tasks: A positron-emission tomography study in normal human subjects.

Neuroscience Letters, 182, 25-28.

Dronkers, N. F. (1996). A new region for coordinating speech articulation. Nature, 384, 159-161.

Eriksson, L., Bohm, C., Kesselberg., M., \& Holte, S. (1988). An automated blood sampling system used in positron emission tomography. Nuclear Science Applications, 3, 133143.

Fiez, J. A. (1997). Phonology, semantics, and the role of the left inferior prefrontal cortex. Human Brain Mapping, 5 , 79-83.

Fiez, J. A., \& Raichle, M. E. (1997). Linguistic processing and the cerebellum: Evidence from clinical and positron emission tomography studies. International Review of Neurobiology, 41, 233-253.

Friston, K. J., Worsley, K. J., Frackowiak, R. S. J., Mazziotta, J. C., \& Evans, A. C. (1994). Assessing the significance of focal activations using their spatial extent. Human Brain Mapping, 1, 210-220.

Frith, C. D., Friston, K. J., Liddle, P. F., Frackowiak, R. S. J. (1991). A PET study of word finding. Neuropsychologia, 29, 1137-1148.
Frith, C. D., Kapur, N., Friston, K. J., Liddle, P. F., \& Frackowiak, R. S. J. (1995). Regional cerebral activity associated with the incidental processing of pseudo-words. Human Brain Mapping, 3, 153-160.

Geschwind, N. (1979). Specializations of the human brain. Scientific American, 241, 158-168.

Hagoort, P. (1993). Impairments of lexical-semantic processing in aphasia: Evidence from the processing of lexical ambiguities. Brain and Language, 45, 189-232.

Hagoort, P. (1997). Semantic priming in Broca's aphasics at a short SOA: No support for an automatic access deficit. Brain and Language, 56, 287-300.

Hagoort, P., Brown, C. M., \& Swaab, T. Y. (1996). Lexical-semantic event-related potential effects in patients with left hemisphere lesions and aphasia, and patients with right hemisphere lesions without aphasia. Brain, 119, 627-649.

Heinze, H. J., Mangun, G. R., Burchert, W., Hinrichs, H., Scholz, M., Münte, T. F., Gös, A., Scherg, M., Johannes, S., Hundeshagen, H., Gazzaniga, M. S., \& Hillyard, S. A. (1994). Combined spatial and temporal imaging of brain activity during visual selective attention in humans. Nature, 372, 543-546.

Herbster, A. N., Mintun, M. A., Nebes, R. D., \& Becker, J. T. (1997). Regional cerebral blood flow during word and nonword reading. Human Brain Mapping, 5, 84-92.

Herholz, K., Pietrzyk, U., Karbe, H., Würker, M., Wienhard, K., \& Heiss, W-D. (1994). Individual metabolic anatomy of repeating words demonstrated by MRI-guided positron emission tomography. Neuroscience Letters, 182, 47-50.

Herzog, H., Seitz, R. J., Tellmann, L., Schlaug, G., \& Müller-Gärtner, H. W. (1996). Quantitation of regional cerebral blood flow using an autoradiographic-dynamic approach in positron emission tomography. Journal of Cerebral Blood Flow and Metabolism, 16, 645-649.

Howard, D., Patterson, K., Wise, R., Brown, W. D., Friston, K., Weiller, C., \& Frackowiak, R. (1992). The cortical localization of the lexicons. Brain, 115, 1769-1782.

Indefrey, P. I., Kleinschmidt, A., Merboldt, K-D., Krüger, G., Brown, C., Hagoort, P., \& Frahm, J. (1997). Equivalent responses to lexical and nonlexical visual stimuli in occipital cortex: A functional magnetic resonance imaging study. Neuroimage, 5, 78-81.

Indefrey, P. I., \& Levelt, W. J. M. (in press). Language production. In M. S. Gazzaniga (Ed.), The cognitive neurosciences, 2nd ed. Cambridge, MA: MIT Press.

Katz, L., \& Feldman, L. B. (1983). Relation between pronunciation and recognition of printed words in deep and shallow orthographies. Journal of Experimental Psychology: Learning, Memory, and cognition, 9, 157-166.

Kuriki, S., Hirata, Y., Fujimaki, N., \& Kobayashi, T. (1996). Magnetoencephalographic study on the cerebral neural activities related to the processing of visually presented characters. Cognitive Brain Research, 4, 185-199.

Law, I., Kannao, I., Fujita, H., Lassen, N. A., Miura, S., \& Uemura, K. (1991). Left supramarginal/angular gyri activation during reading of syllabograms in the Japanese language. Journal of Neurolinguistics, 6, 243-251.

Levelt, W. J. M., \& Wheeldon, L. (1994). Do speakers have access to a mental syllabary? Cognition, 50, 239-269.

Luria, A. R. (1947). Traumatic aphasia. Reprinted in translation. The Hague: Mouton.

McClelland, J. L., \& Rumelhart, D. E. (1981). An interactive activation model of context effects in letter perception. 1. An account of basic findings. Psychological Review, 88, 375-407.

Menard, M. T., Kosslyn, S. M., Thompson, W. L., Alpert, N. M., \& Rauch, S. L. (1996). Encoding words and pictures: A posi- 
tron emission tomography study. Neuropsychologia, 34 , 185-194.

Monsell, S., Patterson, K. E., Graham, A., Hughes, C. H., \& Milroy, R. (1992). Lexical and sublexical translation of spelling to sound: Strategic anticipation of lexical status. Journal of Experimental Psychology: Learning, Memory, and Cognition, 18, 452-467.

Nobre, A. C., Allison, T., \& McCarthy, G. (1994). Word recognition in the human inferior temporal lobe. Nature, 372, 260-263.

Olesen, J. (1974). Cerebral blood flow methods for measurement regulation effects of drugs and changes in disease. Copenhagen: Fadls Forlag.

Oldfield, R. C. (1971). The assessment and analysis of handedness: The Edinburgh inventory. Neuropsychologia, 9, 97113.

Ostrin, R. K., \& Tyler, L. K. (1993). Automatic access to lexical semantics in aphasia: Evidence from semantic and associative priming. Brain and Language, 45, 147159.

Paulesu, E., Frith, C. D., \& Frackowiak, R. S. J. (1993). The neural correlates of the verbal component of working memory. Nature, 362, 342-345.

Perfetti, Ch. A. (1999). Comprehending written language: A blueprint of the reader. In C. M. Brown \& P. Hagoort (Eds.), The neurocognition of language (pp. 167-208). Oxford, UK: Oxford University Press.

Petersen, S. E., Fox, P. T., Posner, M. I., Mintun, M., \& Raichle, M. E. (1988). Positron emission tomographic studies of the cortical anatomy of single word processing. Nature, 331, 585-589.

Petersen, S. E., Fox, P. T., Posner, M. I., Mintun, M., \& Raichle, M. E. (1989). Positron emission tomographic studies of the processing of single words. Journal of Cognitive Neuroscience, $1,153-170$.

Petersen, S. E., Fox, P. T., Snyder, A. Z., \& Raichle, M. E. (1990). Activation of extrastriate and frontal cortical areas by visual words and word-like stimuli. Science, 249, 10411044.

Pitt, M. A., \& McQueen, J. M. (1998). Is compensation for coarticulation mediated by the lexicon? Journal of Memory and Language, 39, 347-370.

Posner, M. I., \& Raichle, M. E. (1994). Images of mind. New York: Scientific American Library.

Price, C. J., Moore, C. J., \& Frackowiak, R. S. J. (1996). The effects of varying stimulus rate and duration on brain activity during reading. Neuroimage, $3,40-52$.

Price, C. J., Moore, C. J., Humphreys, G. W., \& Wise, R. S. J. (1997). Segregating semantic from phonological processes during reading. Journal of Cognitive Neuroscience, 9, 727-733.

Price C. J., Wise, R. J. S., \& Frackowiak, R. S. J. (1996). Demonstrating the implicit processing of visually presented words and pseudowords. Cerebral Cortex, 6, 62-70.

Price, C. J., Wise, R. J. S., Watson, J. D. G., Patterson, K., Howard, D., \& Frackowiak, R. S. J. (1994). Brain activity during reading: The effects of exposure duration and task Brain, 117, 1255-1269.

Pugh, K. R., Shaywitz, B. A., Shaywitz, S. E., Constable, R. T., Skudlarski, P., Fulbright, R. K., Bronen, R. A., Shankweiler, D. P., Katz, L., Fletcher, J. M., \& Gore, J. C. (1996). Cerebral organization of component processes in reading. Brain, 119, 1221-1238.

Roland, P. E., Levin, B., Kawashima, R., \& Akerman, S. (1993). Three-dimensional analysis of clustered voxels in ${ }^{15} \mathrm{O}-\mathrm{bu}-$ tanol brain activation images. Human Brain Mapping, 1, 3-19.
Rota Kops, E., Herzog, H., Schmid, A., Holte, S., \& Feinendegen, L. E. (1990). Performance characteristics of an eightring whole body PET scanner.Journal of Computer Assisted Tomography, 14, 437-445.

Rumsey, J. M., Horwitz, B., Donohue, B. C., Nace, K., Maisog, J. M., \& Andreason, P. (1997). Phonological and orthographic components of word recognition: A PET-rCBF study. Brain, 120, 739-759.

Sakurai, Y., Momose, T., Iwata, M., Watanabe, T., Ishikawa, T., \& Kanazawa, I. ( 1993). Semantic process in kana word reading: Activation studies with positron emission tomography. NeuroReport, 4, 327-330.

Sakurai, Y., Toshimitsu, M., Iwata, M., Watanabe, T., Ishikawa, T., Takeda, K., \& Kanazawa, I. (1992). Kanji word reading process analyzed by positron emission tomography. NeuroReport, 3, 445-448.

Schiller, N. O. (1997). The role of the syllable in speech production: Evidence from lexical statistics, metalinguistics, masked priming, and electromagnetic midsagittal articulography. Published doctoral dissertation. Nijmegen: MPI Series in Psycholinguistics.

Schiller, N. O. (1998). The effect of visually masked syllable primes on the naming latencies of words and pictures. Journal of Memory and Language, 39, 489-507.

Schiller, N. O., Meyer, A. S., Baayen, R. H., \& Levelt, W. J. M. (1996). A comparison of lexeme and speech syllables in Dutch.Journal of Quantitative Linguistics, 3, 8-28.

Seidenberg, M. S. (1987). Sublexical structures in visual word recognition: Access units or orthographic redundancy? In M. Coltheart (Ed.), Attention and performance XII: Reading (pp. 245-263). Hillsdale, NJ: Erlbaum.

Seitz, R. J., Bohm, C., Greitz, T., Roland, P. E., Eriksson, L., Blomkvist, G., Rosenkvist, G., \& Nordell, B. (1990). Accuracy and precision of the computerized brain atlas programme for localization and quantification in positron emission tomography. Journal of Cerebral Blood Flow and Metabolism, 10, 443-457.

Seitz, R. J., Canavan, A. G. M., Yágüez, L., Herzog, H., Tellmann, L., Knorr, U., Huang, Y., \& Hömberg, V. (1997). Representations of graphomotor trajectories in the human parietal cortex: Evidence for controlled processing and automatic performance. European Journal of Neuroscience, 9, 378-389.

Sergent, J., Zuck, E., Levesque, M., \& MacDonald, B. (1992). Positron emission tomography study of letter and object processing: Empirical findings and methodological considerations. Cerebral Cortex, 2, 68-80.

Shaywitz, B. A., Shaywitz, S. E., Pugh, K. R., Constable, R. T., Skudlarski, P., Fullbright, R. K., Bronen, A., Fletcher, J. M., Shankweiler, D. P., Katz, L., \& Gore, J. C. (1995). Sex differences in the functional organization of the brain for language. Nature, 373, 607-609.

Shulman, G. L., Buckner, R. L., Corbetta, M., Miezin, F. M., Raichle, M. E., \& Petersen, S. E. (1996). Consistent cortical blood flow decreases during active visual tasks relative to passive viewing. Neuroimage, 3, S197.

Shulman, G. L., Corbetta, M., Buckner, R. L., Raichle, M. E., Fiez, J. A., Miezin, F. M., \& Petersen, S. E. (1997). Top down modulation of early sensory cortex. Cerebral Cortex, 7 , 193-206.

Steingrüber, H. J. (1971). Zur messung der händigkeit. Zeitschrift für Experimentelle und Angewandte Psychologie, 18, 337-357.

Talairach, J., \& Tournoux, P. (1988). Co-planar stereotaxic atlas of the buman brain: 3-dimensional proportional system: An approach to cerebral imaging. Stuttgart: G. Thieme. 
Thurfjell, L., Bohm, C., \& Bengtsson, E. (1995). CBA-an atlas based software tool used to facilitate the interpretation of neuroimaging data. Computer Methods \& Programs in Biomedicine, 47, 51-71.

Vitevitch, M. S., \& Luce, P. A. (1998). When words compete: Levels of processing in spoken word perception. Psychological Science, 9, 325-329.

Vitevitch, M. S., Luce, P. A., Charles-Luce, J., \& Kemmerer, D. (1997). Phonotactics and syllable stress: Implications for the processing of spoken nonsense words. Language and Speech, 40, 47-62.

Wise, R., Chollet, F., Hadar, U., Friston, K., Hoffner, E., \& Frackowiak, R. (1991). Distribution of cortical neural networks involved in word comprehension and word retrieval. Brain, 114, 1803-1817.
Worsley, K. J., Evans, A. C., Marrett, S., \& Neelin, P. (1992). A three-dimensional statistical analysis for CBF activation studies in human brain. Journal of Cerebral Blood and Metabolism, 12, 900-918.

Zatorre, R. J., Evans, A. C., Meyer, E., \& Gjedde, A. (1992). Lateralization of phonetic and pitch processing in speech perception. Science, 256, 846-849.

Zatorre, R. J., Meyer, E., Gjedde, A., \& Evans, A. C. (1996). PET studies of phonetic processing of speech: Review, replication, and reanalysis. Cerebral Cortex, 6, 21-30.

Zwitserlood, P., Schriefers, H., Lahiri, A., \& van Donselaar, W. (1993). The role of syllables in the perception of spoken Dutch.Journal of Experimental Psychology: Learning, Memory, and Cognition, 19, 260-271. 